\title{
Controlled self-assembled coordination polymer and monomer by $\left[\mathrm{Ni}(\mathrm{mnt})_{2} \mathrm{Cu}_{4} \mathrm{I}_{4}\right]^{2^{-}}$
}

Kunihisa Sugimoto ${ }^{1}$, Masahiko Maekawa ${ }^{2}$, Takayoshi Kuroda-Sowa ${ }^{3}$

${ }^{1}$ Research \& Utilization Division, Japan Synchrotron Radiation Research Institute, Hyogo, Japan, ${ }^{2}$ Research Institute for Science and Technology, Kindai University, Higashi-Osaka, Japan, ${ }^{3}$ Faculty of Science and Engineering, Kindai University, Higashi-Osaka, Japan E-mail: ksugimoto@spring8.or.jp

The construction of coordination polymers based on metal ions and bridging organic ligands is one of the most attractive areas in materials research. So far, we have reported the synthesis and structures of mixed metal coordination polymers $\left(\mathrm{NBu}_{4}\right)_{2}\left[\mathrm{Ni}(\mathrm{mnt})_{2} \mathrm{Cu}_{4} \mathrm{I}_{4}\right](1 ; \mathrm{mnt}=1,2$-dicyano-1,2-ethylene-dithiolate) [1]. The crown motif in complex 1 consists of an eight-membered $\mathrm{Cu}_{4} \mathrm{I}_{4}$ ring, which is supported by the four sulfur atoms of the $\mathrm{Ni}(\mathrm{mnt})_{2}$ moiety. In general, the Cu $4 \mathrm{I}_{4}$ units display a cubane- or step-like arrangement [2]. This type of crown motif containing the $\mathrm{Cu}_{4} \mathrm{I}_{4}$ ring was first found in complex 1. Moreover, complex 1 formed coordination polymers having doubly bridged 1-D chains, in which two copper atoms are coordinated to the nitrogen atoms of the cyano groups of the neighboring $\mathrm{Ni}(\mathrm{mnt}) 2 \mathrm{moieties.} \mathrm{In} \mathrm{this} \mathrm{work,} \mathrm{we}$ successfully controlled the crystal structure of the $\left[\mathrm{Ni}(\mathrm{mnt})_{2} \mathrm{Cu}_{4} \mathrm{I}_{4}\right]$ building unit, and we report the structures of controlled self-assembled coordination polymer $\left[\mathrm{Na}(\mathrm{THF}){ }_{7} \mathrm{Ni}(\mathrm{mnt})_{2} \mathrm{Cu}_{4} \mathrm{I}_{4}\right] \cdot(\mathrm{THF})$ (2) with 2-D sheets and monomer $[\mathrm{Na} 2(18-\mathrm{crown}-6)$ $\left.(\mathrm{THF})_{2}\right]_{2}\left[\mathrm{Ni}(\mathrm{mnt})_{2} \mathrm{Cu}_{4} \mathrm{I}_{4}\right](3)$, containing the eight-membered $\mathrm{Cu}_{4} \mathrm{I}_{4}$ ring crown motif. X-ray diffraction analysis of tiny single crystals of complexes 2 and 3 was performed at the BL02B1 beamline at the SPring- 8 synchrotron radiation facility. Copper and iodine atoms are alternately connected within the eight-membered ring structure, as in complex 1 . The copper atom is coordinated to the nitrogen atom of the cyano group of the neighboring molecule, which is a doubly bridged anionic 1-D polymer consisting of $\left[\mathrm{Ni}(\mathrm{mnt})_{2} \mathrm{Cu}_{4} \mathrm{I}_{4}\right]^{2-}$ units. In complex 2 , the cyano groups of the $\left[\mathrm{Ni}(\mathrm{mnt}){ }_{2} \mathrm{Cu}_{4} \mathrm{I}_{4}\right]^{2-}$ units of neighboring 1-D chains are bridged by sodium atoms, resulting in the formation of a doubly bridged 2-D sheet structure, as shown in Figure. The synthesis of complex 3 using 18-crown-6 ether, details of the molecular structure, and possible applications of the eight-membered $\mathrm{Cu}_{4} \mathrm{I}_{4}$ ring crown motif will be presented.

[1] Sugimoto K. et al. (1999). Chem. Commun. 455-456.

[2] Peng R. et al. (2010). Coord. Chem. Rev. 254, 1-18.

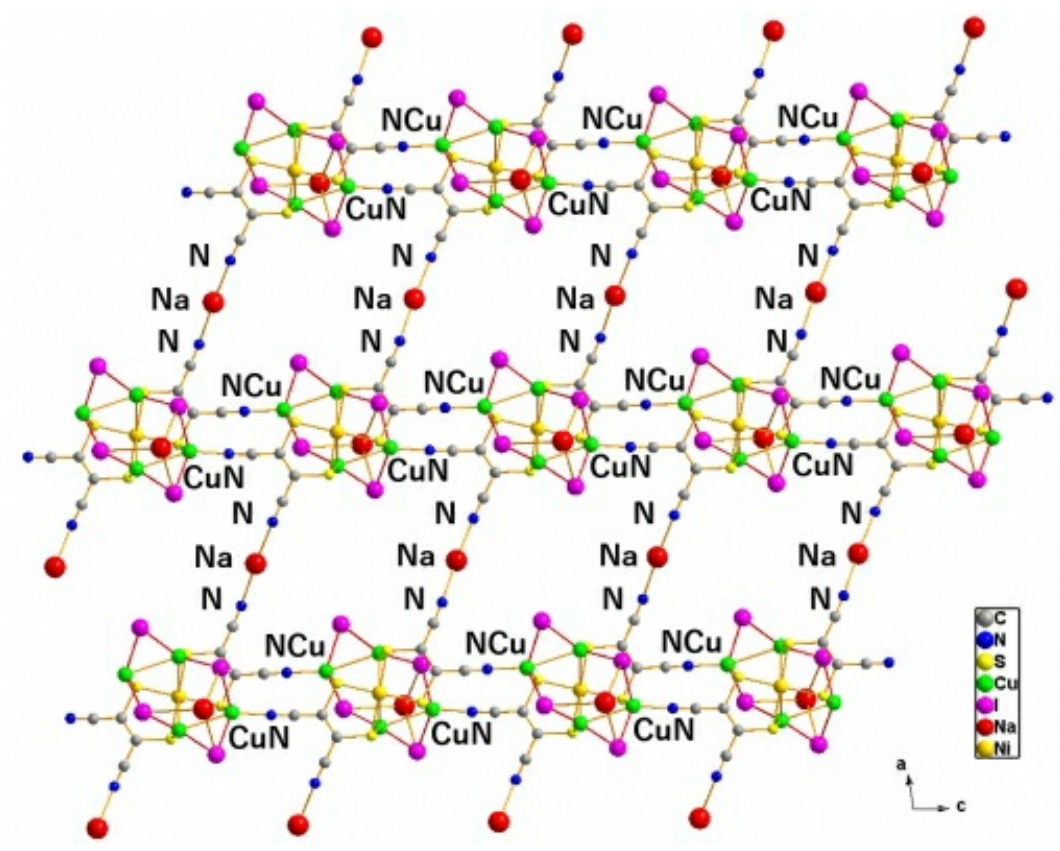

Keywords: Self-assembly, Coordination Polymer, Monomer 